УАK 338.48

ББК 65.433

DOI 10.22394/1682-2358-2021-4-96-106

M.V. Zhukova, post-graduate student of the Sociology and Information Technology Department, Central Russian Institute of Management, Branch of the Russian Presidential Academy of National Economy and Public Administration

A.N. Karlov, post-graduate student of the Management and Public Administration Department, Central Russian Institute of Management, Branch of the Russian Presidential Academy of National Economy and Public Administration

\section{MAIN DIRECTIONS OF TOURISM SECTOR DEVELOPMENT IN A REGION \\ (Case Study of the Orel Region)}

Current conditions that determine the widespread development of domestic tourism, the search for new tourist products and services within the state are considered. The empirical basis of this article is the results of a sociological study of the main directions of the development of domestic tourism, conducted in April 2021 at the Department of Sociology and Information Technologies. It is summarized that improving the quality of tourist services, as well as complete and accessible information about tourist products will help to increase demand in the region by attracting potential tourists.

Key words and word-combinations: regional tourism, tourism sector, tourist activity.
M.В. ЖКукоһа, аспирант кафедро сочиологии и информачионньх технологий Среднерусского института управления - филиала Российской академии народного хозяйства и государственной службь при Президенте РФ (email: filimonovamaria1995@yandex.ru)

A.Н. Карлов, аспирант кафедри менеджмента и государственного управления Среднерусского института управления - филиала Российской академии народного хозяйства и государственной службь при Президенте РФ (eтаil: karlovan785@rambler.ru)

\section{ОСНОВНЫЕ НАПРАВАЕНИЯ РАЗВИТИЯ ТУРИСТИЧЕСКОЙ СФЕРЫ РЕГИОНА \\ (по материалам Орловской области)}

Аннотация. Рассматриваются современные условия, обуславливающие широкое развитие внутреннего туризма, поиск новых туристических продуктов и услуг в пределах России. Эмпирическую основу исследования составили результаты социологического опроса основных направлений развития внутреннего туризма, проведенного в апреле 2021 г. Сделан вывод, что улучшение качества предоставления туристических услуг, а также полная и доступная информация о туристических продуктах будут способствовать увеличению спроса в регионе потенциальных туристов.

Ключевые слова и словосочетания: региональный туризм, туристическая сфера, туристическая активность, Орловская область.<smiles>[AlH2]</smiles>

андемия COVID-19 стала сдерживающим фактором во многих соци- 
ально-экономических сферах жизнедеятельности во всем мире. Туризм оказался одной из самых уязвимых отраслей в 2019-2021 гг. Аостаточно развитые направления внешнего туризма сменились поиском качественного внутреннего туристического продукта.

Вопрос социально-экономического развития сферы туризма в России с каждым годом приобретает все большую актуальность. В периол 2019-2021 гг. развитие внутреннего туризма стало не просто возможностью Аля повышения соџиально-экономического бцагосостояния территорий, но и необходимостью в связи с пандемией. Вектор решаемых государством задач развития смежных с туризмом секторов экономики, привлечения инвестиций в сферу туристического бизнеса, формирование новых рабочих мест смещается в сторону создания конкретных конкурентоспособных туристических продуктов, поА которыми понимается использование туристического потенциала регионов.

Исходя из норм Федерального закона «Об основах туристической деятельности в Российской Федерации», внутренний туризм - это временные выезды (путешествия) в пределах территории государства миџ, постоянно проживающих в России, в кечебно-оздоровительных, рекреационных, познавательных, физкультурно-спортивных, профессионально-деловых и иных целях без занятия деятельностью, связанной с получением дохода от источников в месте временного пребывания [1].

Эксперты подтверждают необходимость качественных перемен в туристической индустрии, которые Аолжны касаться уже не столько законодательной базы или туристических агентств и организаций, сколько развития и повышения качества продуктов и услуг.

Основные направления и особенности развития сферы туризма в Российской Федерации характеризуют следующие факторы:

- государственный и региональный потенџиал соџиально-культурного и исторического наследия с особенностями природно-кмиматического и географического характера, направленный на развитие и удовлетворение потребностей и интересов российских и иностранных туристов;

- повышение спроса на внутренний туризм обусловлено всеобщей эпидемиологической ситуацией и связанным с ней уменьшением возможностей выездного туризма;

- сокрашение выездного туризма Аля соотечественников не отменяет возможность увеличения въездного туризма в Россию дия иностранцев.

Развитие туризма требует комплексного подхода к решению задач транспортных передвижений и размешения туристов, обеспечения Ао- 
ступности разнообразия досугово-развлекательных мероприятий с учетом соответствия цены качеству предоставления различных видов ускуг Аля всех социальных категорий туристов.

Эксперты выделяют следующие наиболее перспективные туристические направления в российских регионах: спортивно-развлекательный и экстремальный туризм; событийный и гастрономический туристический отдых; туризм Амя бизнеса; мечебно-рекреационный туризм; сельский или экологический туризм; Аля жителей городов - поезАки в выходные Ани [2].

В современных условиях предполагается рост спроса на туризм, при котором совмещается отдых и работа, что возможно при дистанционном ведении профессиональной деятельности. Развитие туристического отдыха должно быть направленно на создание безопасных условий в периол АОАгого отАыха, с возможностью беспрерывной работы онлайн. Аля обеспечения данных направлений требуется высокий уровень интернет-сервисов, автоматизации и бесконтактных сервисов обеспечения.

Необходимость сфокусироваться на вопросах развития регионального туризма подчеркивают эксперты-соџиологи. Согласно комментарию эксперта Центра соџиологических исследований ВЦИОМ И. Гращенкова, "данные нашего исследования свидетельствуют о высоком интересе среди россиян к путешествиям внутри России. Туристические операторы, пострадавшие от роста цен в домарах и евро, также заинтересованы в развитии внутреннего туризма. При этом хорошо известные и освоенные направления - Москва, Петербург, Крым, Сочи - работают на пределе инфраструктурных мощностей. В этой связи Аальнейшее расширение туристических потоков представмяется оптимацьным, прежде всего, за счет освоения новых, пока «нераскрученных» направмений, а не перегрузки «фаворитов» [3] .

Продвижение новых туристических направлений затрудняет ряА факторов, свойственных туристической сфере российских регионов. Трудности в предоставлении качественного туристического продукта обусловлены особенностями развития территорий, решить которые не под силу на региональном уровне.. Необходимо расширение регионального и федерального взаимодействия и государственной подАержки в решении насущных проблем: слабой информированности потенџиальных туристов как внутри регионов, так и в государственных масштабах, касающихся малоизвестных туристических направлений; сложной транспортной доступности; низкого уровня обслуживания обеспечивающих и смежных сфер туризма. 
Стратегия развития внутреннего туризма в России до 2035 г. направмена на привлечение всех групп гражАан Аля совершения путешествий внутри страны, что может быть обеспечено повышением доступности туристических ускуг и продуктов.

ОАнако слабая узнаваемость, отсутствие региональных российских брендов, неустоявшийся или негативный имидж территорий снижает спрос в туристической сфере. Наличие так называемых территорий притяжения отечественных и иностранных туристов, формирующих разнообразные преАложения и туристические продукты, преАназначенные для размичных категорий туристов (детей, молодежи, экстремалов и т.А.), не может справиться с расширяющимся спросом. Возникает необходимость реализации неиспользованного потенциала регионов.

В поисках точек роста для регионального туризма на кафедре социологии и информационных технологий СреАнерусского института управления РАНХиГС было проведено соџиологическое исследование, нацеленное на выявление особенностей туристического поведения жителей региона и возможных путей развития туристической сферы. Эмпирическую базу работы составици результаты соџиологических исследований, проведенных в апреле 2021 г. по региону (Орловской обмасти) под руководством Аоктора социологических наук, профессора А.А. Алексеенок в рамках Гранта Федерального агентства по делам молодежи (Росмолодежь).

Методология исследования включает социологический анализ частотных распределений и таблиц сопряженности ответов на вопросы 302 респондентов - жителей Орловской области в возрасте от 18 мет и старше. Выборка - случайная с точностью $95 \%$ и доверительным интервалом 5\%. Опрос респондентов проходил в дистанционной форме посредством анкетирования с использованием сервиса Яндекс.Формы.

По рялу вопросов проведен сравнительный анализ результатов регионального исследования и исследования ВЦИОМ, основанного на всероссийской выборке [4] .

Региональный туризм, за искмючением популярных туристических центров (Краснодарский край, Республика Крым, г. Москва, г. СанктПетербург и т.п.), остается потенциальным ресурсом дия развития внутреннего туризма России. Туристическая активность населения Ормовской области представлена на рис. 1.

По данным социологического исследования, каждый десятый жкитель Орловской области, как правило, не совершает туристических поездок. Туристически активные миџа в последние пять мет отправцяются 
в поездки периодически, время от времени. Чуть менее одной трети респондентов $(28,5 \%)$ вообще не ездят с целью туризма по Орловской области, хотя входят в число туристически активного населения и рассматриваются как потенциальные туристы региона при определенных условиях.

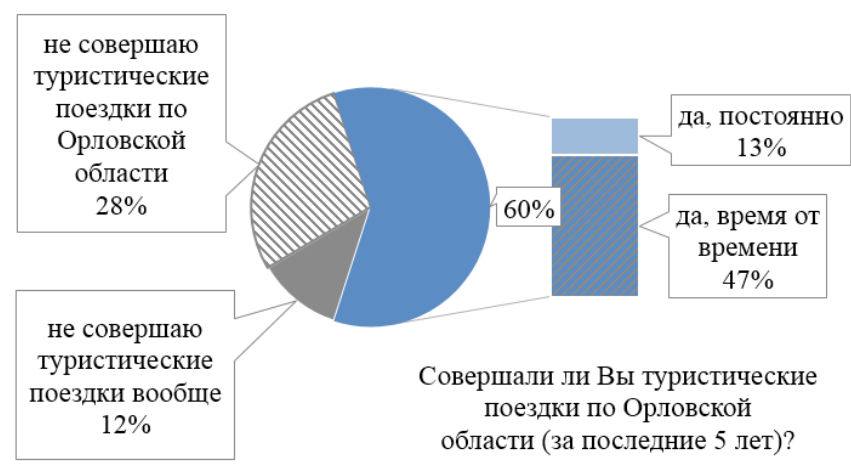

Рис. 1. Туристическая активность населения Орловской области

Основные условия дмя развития туризма в регионе были выяснены в ходе анациза таблиц сопряженности ответов на вопрос об основных аспектах, на которые обращают или обратят (Аля тех, кто пока не совершает турпоезки по региону) внимание респонденты при выборе места отдыха в Орловской области в зависимости от уровня туристической активности в регионе (табц. 1).

В целом наиболее важными основаниями выбора места туристического направления в регионе явцяются его важнейшие особенности: общая стоимость поездки; транспортная доступность места отдыха; развитость Аосуговой инфраструктуры. Те, кто совершает туристические поездки по Орловской области, чаще отмечают как необходимые составмяющие туристического отдыха материальное наследие и природные мандшафты. Те, кто не совершает туристические поездки по региону, ценят в большей степени стоимость поездки и развитость досуговой инфраструктуры в месте отдыха. Следовательно, именно данные аспекты туристического отдыха в регионе не устраивают потенциацьных туристов и служат фактором мля выбора иных туристических направлений.

100 Bulletin of the Volga Region Institute of Administration • 2021. Vol. 21. № 4 
Таблица 1

На что обращают (обратят) внимание в первую очередь при выборе места отдыха в Орловской области те, кто совершает, и те, кто не совершает, туристические поездки по региону, \%

Несколько вариантов ответа

\begin{tabular}{|c|c|c|}
\hline $\begin{array}{c}\text { Варианты ответов на вопрос: «На что } \\
\text { вы обращаете (обратите) внимание } \\
\text { в первую очередь при выборе места } \\
\text { отдыха в Орловской области?» }\end{array}$ & $\begin{array}{c}\text { Те, кто совершает } \\
\text { туристические } \\
\text { поездки по } \\
\text { региону }\end{array}$ & $\begin{array}{c}\text { Те, кто не } \\
\text { совершает } \\
\text { туристические } \\
\text { поездки по региону }\end{array}$ \\
\hline $\begin{array}{l}\text { Общая стоимость туристической } \\
\text { поездки (включая проживание, } \\
\text { проезд, питание) }\end{array}$ & 48,1 & 54,7 \\
\hline $\begin{array}{l}\text { Транспортная доступность места } \\
\text { отдыха (время в пути, качество } \\
\text { транспортной инфраструктуры, } \\
\text { удобство и проч.) }\end{array}$ & 53,6 & 34,4 \\
\hline $\begin{array}{l}\text { Развитость досуговой } \\
\text { инфраструктуры (есть куда сходить, } \\
\text { что посмотреть, предусмотрены ли } \\
\text { развлечения для детей и для взрослых } \\
\text { и проч.) }\end{array}$ & 43,1 & 51,2 \\
\hline $\begin{array}{l}\text { Комфорт размещения (в том числе } \\
\text { возможность выбора из нескольких } \\
\text { вариантов) }\end{array}$ & 27,6 & 34,9 \\
\hline Качество обслуживания, сервис & 29,3 & 22,1 \\
\hline Доступность и качество питания & 17,1 & 18,6 \\
\hline $\begin{array}{l}\text { Материальное наследие (архитектура, } \\
\text { памятники, музеи и проч.) }\end{array}$ & 38,7 & 22,1 \\
\hline $\begin{array}{l}\text { Нематериальное наследие (язык, } \\
\text { традиции и проч.) }\end{array}$ & 4,4 & 7,0 \\
\hline $\begin{array}{l}\text { Природные ландшафты (наличие } \\
\text { озер, рек, лесов и проч.) }\end{array}$ & 35,4 & 22,1 \\
\hline $\begin{array}{l}\text { Проведение культурно-массовых } \\
\text { мероприятий (фестивали, ярмарки, } \\
\text { выставки, проч.) }\end{array}$ & 19,9 & 19,8 \\
\hline
\end{tabular}


В табл. 2 представлена оценка основных аспектов туристического отдыха. Таблица сопряженности характеризует разницу в оџенках тех, кто совершали хотя бы одну поездку по региону, и респондентов, не совершающих туристических поездок в пределах Ормовской области.

Таблица 2

Аспекты туристического отдыха в Ормовской области в оџенках респондентов

\begin{tabular}{|c|c|c|c|}
\hline $\begin{array}{c}\text { Аспект отдыха, оцениваемого } \\
\text { респондентами по } \\
\text { пятибалльной шкале } \\
\text { (5 - отлично, } 1 \text { - очень плохо) }\end{array}$ & $\begin{array}{c}\text { Те, кто совершает } \\
\text { туристические поездки } \\
\text { по региону постоянно } \\
\text { или время от времени, } \\
\text { \% } \\
\end{array}$ & $\begin{array}{c}\text { Те, кто не совершает } \\
\text { туристические } \\
\text { поездки по } \\
\text { Орловской области, } \\
\text { \% } \\
\end{array}$ & $\begin{array}{l}\text { Среднее } \\
\text { значение }\end{array}$ \\
\hline 1 & 2 & 3 & 4 \\
\hline \multicolumn{4}{|c|}{ Стоимость туров } \\
\hline 1 & 2,2 & 10,5 & \multirow{5}{*}{2,7} \\
\hline 2 & 8,3 & 5,8 & \\
\hline 3 & 34,8 & 25,6 & \\
\hline 4 & 28,2 & 25,6 & \\
\hline 5 & 11,6 & 4,7 & \\
\hline \multicolumn{3}{|c|}{ Комфортное проживание } & \multirow{6}{*}{2,8} \\
\hline 1 & 4,4 & 12,8 & \\
\hline 2 & 9,4 & 8,1 & \\
\hline 3 & 31,5 & 22,1 & \\
\hline 4 & 34,3 & 27,9 & \\
\hline 5 & 8,8 & 5,8 & \\
\hline \multicolumn{4}{|c|}{ Возможность улучшения здоровья, лечения } \\
\hline 1 & 6,1 & 15,1 & \multirow{5}{*}{2,5} \\
\hline 2 & 12,7 & 4,7 & \\
\hline 3 & 34,8 & 33,7 & \\
\hline 4 & 23,8 & 15,1 & \\
\hline 5 & 8,3 & 8,1 & \\
\hline \multicolumn{4}{|c|}{ Качество питания } \\
\hline 1 & 2,2 & 7,0 & \multirow{5}{*}{3,2} \\
\hline 2 & 7,7 & 7,0 & \\
\hline 3 & 30,9 & 22,1 & \\
\hline 4 & 35,9 & 37,2 & \\
\hline 5 & 17,7 & 10,5 & \\
\hline \multicolumn{4}{|c|}{ Качество обслуживания, сервис: } \\
\hline 1 & 3,9 & 8,1 & \multirow{5}{*}{3,0} \\
\hline 2 & 7,7 & 9,3 & \\
\hline 3 & 34,3 & 24,4 & \\
\hline 4 & 38,1 & 34,9 & \\
\hline 5 & 10,5 & 7,0 & \\
\hline
\end{tabular}


Окончание табл. 2

\begin{tabular}{|c|c|c|c|}
\hline $\begin{array}{c}\text { Аспект отдыха, оцениваемого } \\
\text { респондентами по } \\
\text { пятибалльной шкале } \\
\text { (5- отлично, } 1 \text { - очень плохо) }\end{array}$ & \begin{tabular}{|c|} 
Те, кто совершает \\
туристические поездки \\
по региону постоянно \\
или время от времени, \\
$\%$ \\
\end{tabular} & $\begin{array}{c}\text { Те, кто не совершает } \\
\text { туристические } \\
\text { поездки по } \\
\text { Орловской области, } \\
\text { \% } \\
\end{array}$ & $\begin{array}{l}\text { Среднее } \\
\text { значение }\end{array}$ \\
\hline \multicolumn{4}{|c|}{ Гостеприимство местного населения } \\
\hline 1 & 1,7 & 8,1 & \multirow{5}{*}{3,4} \\
\hline 2 & 7,2 & 11,6 & \\
\hline 3 & 16,0 & 20,9 & \\
\hline 4 & 33,7 & 24,4 & \\
\hline 5 & 35,9 & 20,9 & \\
\hline \multicolumn{4}{|c|}{ Наличие доступных развлечений, возможность культурного досуга } \\
\hline 1 & 3,3 & 14,0 & \multirow{5}{*}{3,2} \\
\hline 2 & 11,6 & 9,3 & \\
\hline 3 & 28,7 & 24,4 & \\
\hline 4 & 34,3 & 23,3 & \\
\hline 5 & 17,7 & 15,1 & \\
\hline \multicolumn{4}{|c|}{ Безопасность отдыхающих } \\
\hline 1 & 2,8 & 5,8 & \multirow{5}{*}{3,2} \\
\hline 2 & 6,6 & 8,1 & \\
\hline 3 & 28,2 & 23,3 & \\
\hline 4 & 39,8 & 26,7 & \\
\hline 5 & 17,7 & 16,3 & \\
\hline
\end{tabular}

Возможность узнать новое, побывать в интересных местах

\begin{tabular}{|c|c|c|c|}
\hline 1 & 1,7 & 10,5 & \multirow{5}{*}{3,6} \\
\hline 2 & 5,5 & 7,0 & \\
\hline 3 & 21,5 & 22,1 & \\
\hline 4 & 30,9 & 23,3 & \\
\hline 5 & 38,1 & 24,4 & \\
\hline \multicolumn{4}{|c|}{ Природа и климат } \\
\hline 1 & 0,6 & 3,5 & \multirow{5}{*}{4,1} \\
\hline 2 & 2,8 & 2,3 & \\
\hline 3 & 9,4 & 15,1 & \\
\hline 4 & 37,6 & 37,2 & \\
\hline 5 & 48,6 & 33,7 & \\
\hline
\end{tabular}

\begin{tabular}{|l|c|c|}
\hline \multicolumn{3}{|c|}{ Состояние туристического транспорта } \\
\hline 1 & 6,1 & 14,0 \\
\hline 2 & 12,8 & 12,8 \\
\hline 3 & 32,2 & 29,1 \\
\hline 4 & 29,4 & 17,4 \\
\hline 5 & 10,6 & 9,3
\end{tabular}


Среднее суммарное значение всех предложенных для оценки аспектов туристической сферы региона равно 3,1. «Хорошо» респондентами оценивается такой аспект, как «природа и климат»; «чуть выше среАнего» - «возможность узнать новое, побывать в интересных местах», «гостеприимство местного населения», «качество питания», «наличие Аоступных развлечений, возможность Амя культурного досуга» и «безопасность отдыхающих». Ниже средней оценки получили такие наибомее важные для потенциальных туристов (см. табл. 1) аспекты сферы туризма, как «стоимость туров», «комфортное проживание», а также «состояние туристического транспорта» и «возможность улучшения зАоровья, мечения».

Аля понимания уровня развития туристической сферы в регионе был проведен сравнительный анализ некоторых аспектов регионального (исследование, проведенное на кафеАре социологии и информаџионных технологий) и всероссийского туризма (исследование ВЦИОМ) [4] .

Таблица 3

Средние значения оценок некоторых аспектов туристического отдыха в Орловской области и в России

\begin{tabular}{l|c|c}
\hline \multirow{2}{*}{\multicolumn{1}{c|}{ Аспект отдыха }} & \multicolumn{2}{|c}{ Среднее значение оценок, \% } \\
\cline { 2 - 3 } & $\begin{array}{c}\text { Орловская } \\
\text { область }\end{array}$ & Россия \\
\hline Условия проживания & 2,8 & 3,5 \\
Лечебно-оздоровительные возможности & 2,5 & 3,6 \\
Качество питания & 3,2 & 3,6 \\
Качество обслуживания, сервиса & 3,0 & 3,6 \\
Доступность развлечений и культурно- & 3,2 & 3,8 \\
досуговые возможности & 3,2 & 3,9 \\
Уровень безопасности отдыха & & \\
Возможность узнать новое, побывать в & 3,6 & 4,1 \\
интересных местах & 4,1 & \\
Природно-климатические условия & &
\end{tabular}

Среднее значение оџенок основных составляющих туристического отдыха и досуга Орцовской области ниже, чем средние показатели оценок этих же аспектов в общероссийском масштабе. При этом в аспекте «природа и климат» средние оценки совпадают, а это значит, 
что 6магоприятне природно-кмиматическе и географические усыовия ретиона явмются на данный момент каючевыми толками Ала разиития туризяа. Тем не менее формирование актуамнног турпродукта, который сможет конкурировать с Арутими продуктами на рынке, необходимо строить с учетом проектной деятеньности по блатоустройству и разиитю территорий, разития системи туристической инфраструктуры [5, с. 198]. При этом проектная делтемьность домжна быты напрамена на умушение комфортности прокивания и обеспетение Безопасности отанхавоших.

Ретионамыне про6кемы социалыно-экономического характера не позвомнот сегодня в короткие сроки решить задати, сляланные с проблемами туризма. В цемом по России изменения усмовий дия туристическото отдықа пмевот помокительную тенденцик $(46,3 \%$ респондентов отме-

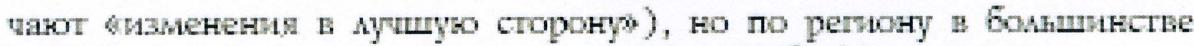
своем таких перемен реслонденты не виднт $(38,4 \%$ ) (рис. 2).

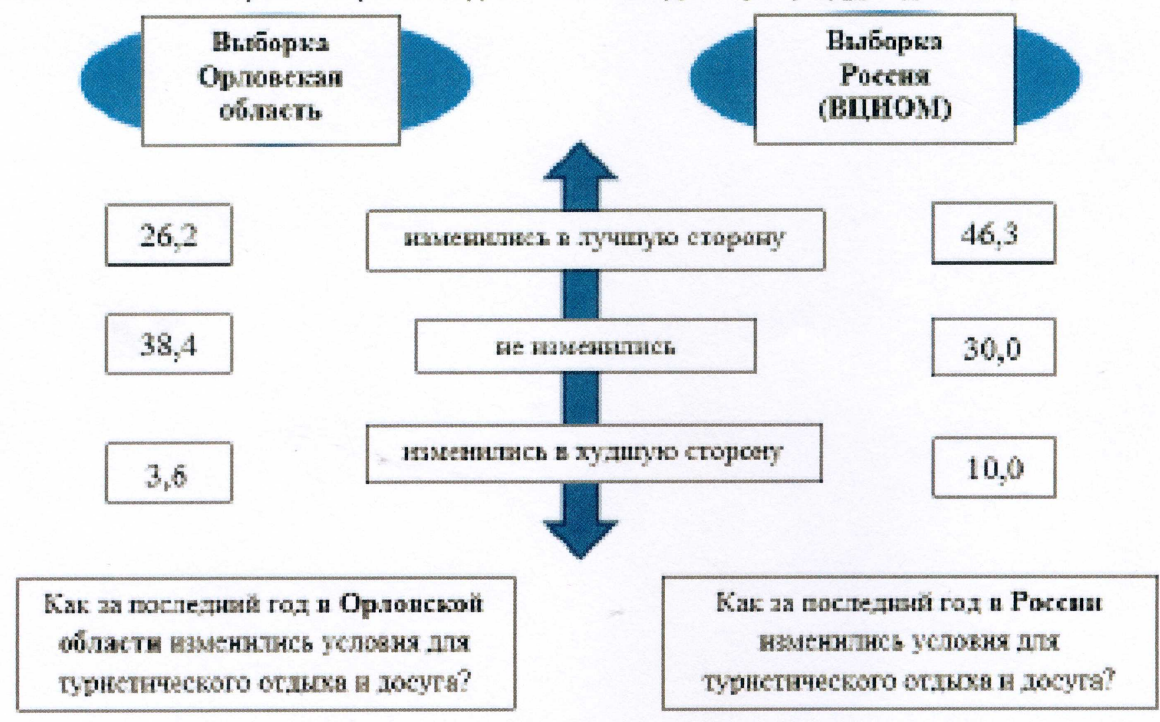

Рис. 2. Изменение условий Ант туристического отднгха и досуга

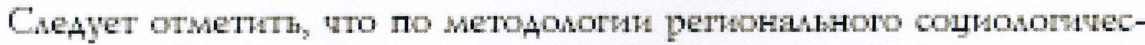
кого исследования предпоматамось вынмение мнений среди тех, кто отмеиает отсутстие изменений, вместе с оценкой ситуации. Так, среди $38,4 \%$ респондентов, отметивших, тто уековия дая туристипеското отдыха и досута не изменились, $18,2 \%$ ситают их хорошими и 20,2\% - плохими. Cмедовательно, возникает задауа не допустить стагнауны разиития региональной туристической оферы. 
Помимо социально-экономической поддержкки туризма, необходимо разработать информационную систему продвижкения туристического продукта региона. В настоящее время, как утверждают респонденты регионального исследования, основными источниками получения информации о возможности проведения туристического отдыха в Орловской области явцяются Арузья, знакомые (так называемое «сарафанное радио» ) $-37,2 \%$ и Интернет $-36,5 \%$ опрошенных. Более того, житеми Орловщины отмечают, что «чем интереснее поезАка, тем почему-то сложнее найти информацию про нее».

Таким образом, в современных условиях регионам Российской ФеАерации, в частности Орловской области, целесообразно использовать уже существующие конкурентные преимущества в сфере внутреннего туризма с учетом исторической ценности территории, ее природнокАиматического потенциала. При этом требуется работать наА улучшением ключевых аспектов туристического отдыха, таких как соответствие цены и качества предоставмяемых услуг, повышение транспортной Аоступности, совершенствование территориальной инфраструктуры, расширение возможностей дмя реализации потребностей разных групп населения в сфере туризма. Преодолению возникшей стагнации развития регионального туризма, привлечению потенциальных туристов, безусловно, способствуют современные маркетинговые и информационные технологии, позволяющие широкий обмен информацией о туристических возможностях регионов.

\section{Библиографический список}

1. Стратегия развития туризма в Российской Федерации на период до 2035 года: утв. распоряжением Правительства РФ от 20 сент. 2019 г. № 2129-p. URL: https:// tourism.gov.ru/upload/iblock/298/Стратегия\%20развития\%20туризма\%20на\%20перио д\%20до\%202035\%20года.pdf

2. Никольская E. Стратегия развития внутреннего туризма в России в 2021 году // Welcome Times: мнения. 2021. 4 марта. URL: https://welcometimes.ru/opinions/strategiya-razvitiya-vnutrennego-turizma-v-rossii-v-2021-godu

3. Аналитический доклад «Внутренний туризм: курс на расширение!» / ВЦИOM: сайт. 2020. 29 янв. URL: https://wciom.ru/analytical-reports/analiticheskii-doklad/ vnutrennij-turizm-kurs-na-rasshirenie

4. Аналитический обзор: «Итоги туристического лета - 2020» / ВЦИОМ: сайт. 2020. 29 сент. URL: https://wciom.ru/analytical-reviews/analiticheskii-obzor/itogi-turisticheskogo-leta-2020

5. Карлов A.Н., Богатырев Р.А. Развитие туризма в Российской Федерации как вектор реализации туристского потенциала в регионах // Среднерусский вестник общественных наук. 2020. Т. 15, № 6. С. 191-200. 